Portland State University

PDXScholar

1977

\title{
Motivational Factors Behind Repetitive Abortions
}

\author{
Kelly Osmont \\ Portland State University \\ Ellen Wolfford \\ Portland State University
}

Follow this and additional works at: https://pdxscholar.library.pdx.edu/open_access_etds

Part of the Medicine and Health Commons, and the Social Work Commons Let us know how access to this document benefits you.

\section{Recommended Citation}

Osmont, Kelly and Wolfford, Ellen, "Motivational Factors Behind Repetitive Abortions" (1977).

Dissertations and Theses. Paper 1918.

https://doi.org/10.15760/etd.1917

This Thesis is brought to you for free and open access. It has been accepted for inclusion in Dissertations and Theses by an authorized administrator of PDXScholar. Please contact us if we can make this document more accessible: pdxscholar@pdx.edu. 


\title{
MOTIVATIONAL FACTORS BEHIND \\ REPETITIVE ABORTIONS
}

\author{
by \\ KELLY OSMONT \\ and \\ ELLEN WOLFFORD
}

A practicum submitted in partial fulfillment of the requirements for the degree of

MASTER OF

SOCIAL WORK

Portland State University

1977 
The advisor approved this practicum presented June 1, 1977.

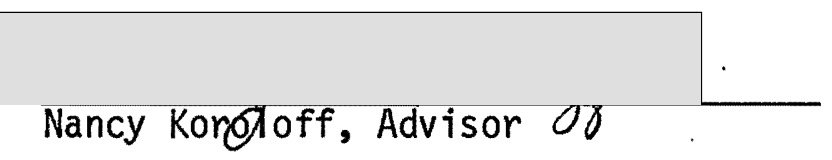




\section{ACKNOWLEDGMENTS}

We would like to express our appreciation to Nancy Koroloff for her support and direction; to Lovejoy Specialty Hospital and the University of Oregon Medical School Outpatient Clinic and Multnomah Hospital for their cooperation and assistance; and to ourselves for our patience and support of one another. 
TABLE OF CONTENTS

PAGE

ACKNOWLEDGEMENTS .................

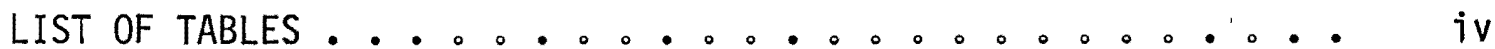

CHAPTER

I INTRODUCTION ............... 1

II REVIEW OF LITERATURE。 ............ 3

III METHODOLOGY ............... 13

Research Design .................. 13

Development of the Questionnaire...... 13

Questionnaire Format. ......... 14

Pre-Test................. 15

Site。.............. 15

Population. . ............. 16

Data Collection ........... 17

Totals of Data Collected. ........ 18

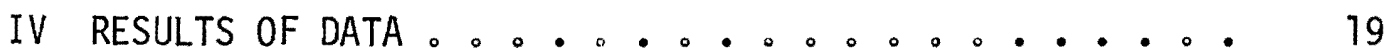

$\checkmark$ CONCLUSIONS AND IMPLICATIONS. ........ 25

Conclusions Regarding Hypotheses....... 25

Limitations of the Study........... 28

Implications for Social Work. ....... 30

BIBLIOGRAPHY ................. 32

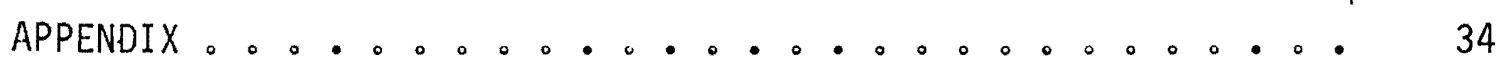




\section{LIST OF TABLES}

PAGE

\section{TABLE}

I Totals of Data Collected ........... 18

II Age of Interviewees ............. 19

II Highest Level of Education Completed ........ 20

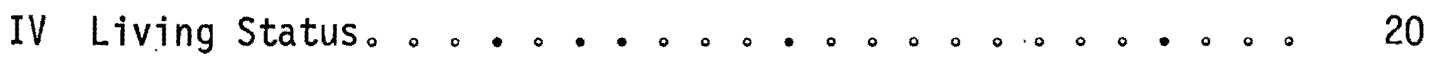

$\checkmark$ Frequency of Live Births Prior to This Abortion...... 21

VI Total Number of Abortions Including Last Abortion. ... 21

VII Frequency of Respondents Having Received Birth Control

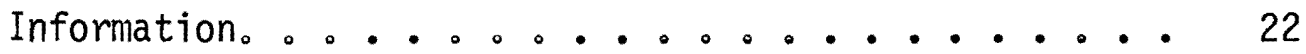

VIII Birth Control Information Received by Respondents. . . . 22

IX Locations of Previous Abortions.........。2 23

$X$ Length of Time Last Repeat Abortions Occurred. . . . . 23

XI Causes Given for Pregnancy ............ 24 


\section{CHAPTER I}

\section{INTRODUCTION}

This practicum intends to explore the motivational factors behind repeat abortions. The underlying assumptions of this study include: (1) women have abortions; (2) women have repeat abortions. Based on these assumptions, the two research questions are (1) are there significant factors in the causation of repeat abortions, and (2) what are the implications regarding the lack of information and service to women which have a direct relationship to repeat abortions.

For the purpose of this study, a repeat abortion will be defined as any abortion occuring after a first abortion. Significant factors in the causation of repeat abortion refers to those reasons behind women repeating an abortion. The fourth assumption is defined as those areas which lack services and information that could effect repeat abortions, such as education, counseling, birth control methods.

It is the personal experience of various counseling agencies that a large amount of women have repeat abortions: approximately $20 \%$. The questionnaire will be administered to only those women who are repeating an abortion. The researchers have chosen two different sites to administer the questionnaire. These sites are the Lovejoy Specialty Hospital and the University of Oregon Medical School Outpatient Clinic and Multnomah Hospital.

Having considered the above assumptions: (1) women have abor- 


\section{CHAPTER II}

\section{REVIEW OF THE LITERATURE}

Since the United States Supreme Court ruled the restrictive abortion laws of Texas and Georgia unconstitutional on January 22, 1973, there has been a rapid increase in legal abortions and a dramatic reduction nationwide in illegal abortions. Dr. Palomaki states that, "Abortion is now one of the most commonly performed procedures in the U.S."1

In evaluating the literature regarding the Court's decision to legalize abortion, it can be seen that it was made on the basis of some very specific, practical and humanistic issues. Chief Justice Douglas in explaining his decision wrote the following:

The Georgia statute is at war with the clear message of these cases, that a woman is free to make the basic decision about whether to bear an unwanted child. Elaborate argument is hardly necessary to demonstrate that childbirth may deprive a woman of her preferred life style and force upon her a radically different and undesirable future. For example, rejected applicants under Georgia statute are required to endure the discomforts of pregnancy, to incur pain, higher mortality rate, and the after effects of childbirth, to abandon educational plans, to sustain loss of income, to forgo the satisfactions of careers, to tax further mental and physical health in providing childcare, and in some cases, to bear the life long stigma of unwed motherhood, a badge which may haunt, if not deter, later legitimate family relationships.2

1"Abortion Techniques: What are their Risks and Complications?" Contemporary Obstetrics and Gynecology, Vo1。9, p。73, 1977.

"Health, Social Impact of Legalized Abortions," Family Planning Digest, Vo1。1, No. 4., pp。13-15, 1972 。 
Beginning 15 to 20 years ago, abortions were performed to preserve the mental life or the health of the mother. Mental life or health was more difficult to define than the physical health of women, and many women were denied abortions when they could not prove their present, or potential instability, if they gave birth to the unwanted child. This may have been an "evolutionary move to circumvent restrictive laws written nearly three-quarters of a century before." ${ }^{3}$

The risks of having an abortion now are much less than when abortions were illegal, but there are still risks involved. The following are the types of procedures available, listed in order of the safest procedure first, to the one with the most risks.

1. A first-trimester suction-curettage abortion performed under a local anesthesia is currently the safest procedure available. This can be done up to 11 weeks gestation. A suction-curettage procedure on a woman under 10 weeks gestation is most likely safer when performed in a reputable, freestanding abortion clinic than in a large institution.

2. Second-trimester abortions should be avoided whenever possible. If it becomes necessary to perform this type of abortion, intraamniotic instillation of prostaglandin $F 2$ is the method of choice. An hysterotomy or hysterectomy are rarely the approaches indicated. ${ }^{4}$

The change in the legality of abortions did not necessarily alter

3 "Professional Perspectives on Abortion," JOGN Nursing, p. 25, 1974. p。73.

"Abortion Techniques: What are their Risks and Complications?" 
attitudes, for there are still many people today who adamantly oppose women having abortions. The legal reform, though, has strengthened the women's rights movement by establishing a woman's right to privacy and control of her own body. In addition, it has recognized the hardships which unwanted births cause to individual women, and given them an option to enduring these hardships 。

Abortion reform has reduced the number of illegal abortions and the suffering and deaths which accompany them, especially in the case of the poor. It has eliminated the extensive discriminatory effects which abortion laws had on the poor. It has provided them with social equality in regards to their family planning, and given them new options for their future.

Abortion reform has increased the availability of family pianning $X$ services for the poor. It has and will continue to save huge welfare costs attributed to the birth and care of welfare babies; decrease the number of unwanted babies who have a greater potential. for maladjustment; and finally, help to break up the vicious circle of births which keep poor families tied to the welfare system.

The previous information has included the basis on which the Supreme Court ruling was made, risks of abortions to women, and the benefits of the legalization of abortions. In addition, the researchers, aware of the time, expense, and physical and emotional risks involved in abortions, have explored the literature to try to discover the possible rationale prompting a woman who already has had one or more abortions, to have another unplanned pregnancy. From this review, we wanted to find significant factors which might lead us to a better 
understanding of motivational factors leading to repeat abortions 。

While there is much research in the literature relating to use or misuse of contraceptives and women seeking a therapeutic abortion, the researchers were only able to find one study which dealt specifically with a patient's seeking a repeat abortion. Nonetheless, the following is a brief survey of the literature showing common factors attributed to the phenomenon of repeat abortions.

The researchers shall first discuss some of the research material from the literature, more in view of its general rather than direct relevance to our study.

The hypotheses of a study done by Keller and Crawford, "Psychological Sources of Resistance to Family Planning", was that psychological factors determined resistance to family planning. They chose as their subjects women between the ages of 20 and 40 years old, fertile, having access to reliable contraceptives, living with their husbands, and having born at least two still-living children by their present husband。 They felt the most important result of their study was that psychological factors were found to be strongly related to contraceptive behavior. Their interpretations were: "Feelings of inefficacy may be related to contraceptive "non-use" in at least two ways. First, birth control measures may not be taken by those who, regardless of their knowledge of contraception, are not inwardly convinced they have the power to so control their lives." ${ }^{5}$ Secondly, procreation of children is one of the few activities from which the desirable feeling of effi-

5 "Psychological Sources of Resistance to Family Planning," Merrill-Palmer Quarterly, Vol. 16, p.299, 1970. 
cacy can be derived. 6

Sanford R. Wolf, M.D. proposes in a paper he wrote that a lack of knowledge does not appear to be the chief reason for contraceptive failures. Because of wide dissemination of birth control information, he states that it is likely that a significant proportion of unwanted pregnancies occur in cases where psychosexual conflicts of one or both . partners were important in the pregnancy. He draws his ideas from unpublished data taken from a large, carefully controlled interview series which examined the psychosocial sequelae to the therapeutic abortion seen at the Center for Social Studies in Human Reproduction at Johns Hopkins University School of Medicine, and also 400 consecutive cases seen in the Pregnancy Counseling Clinic of the University of California. Both of these groups were interviewed during the period of 1970-1971. He concluded that, "Interpersonal situations resulting in contraceptive misuse as described by patients seeking abortion tend to fall into certain patterns and are more common during specific portions of the life cycle, most especially at adolescence. They are also highty dependent on the state of contraceptive technology available at any given time, and upon the prevailing cultural milieu." 7

These patterned behaviours are: (1) Avoidance of birth control. Women's unwillingness to deal realistically with her own sexual desires are in this category. This attitude tends to be most prevalent among

${ }^{6}$ Ibid., p. 299.

7 "Psychosexual Problems Associated with the Contraceptive Practices of Abortion-Seeking Patients", Medical Aspects of Human Sexuality, Vol. VII, No.9, p. 172. 
adults as we11..$^{8}$ He further notes that these women are frequently impulsive in decision-making and fail to use introspection even when dealing with significant events regarding their own health or personal finances. Elements of both groups, those who avoid birth control and those who are impulsive in decision-making, frequently occur in the same women. This category has been noted to have repeat abortions unless intervention induces some degree of insight. ${ }^{9}$

(2) Forgetting the birth control method. This was often found with women- who used birth control pills, for example, as a means of self-punishment, as manipulative behavior of gaining control over a relationship, or as a means of punishing a sexual partner. ${ }^{10}$

(3) Adolescent rebellion. This can take a variety of forms such as the rebelliousness of adolescence itself, to openly abusing contraception as a way to invite control by her parents, to misusing contraceptives to combat parents. ${ }^{11}$

(4) Misuse of contraception in a group "fami 1y". This occurred in groups of people living in close quarters, often under strained or pathologic situations. This type of "family" is more common among the poor white communities. Often some of the members are. legally married. ${ }^{12}$

${ }^{8}$ Ibid., p. 172.

${ }^{9}$ Ibid。, p. 172 .

${ }^{10}$ Ibid., p. 173.

11 Ibid., p.174。

12 Ibid., p. 178. 
(5) Adultery by the wife following vasectomy. These occur on a smaller basis than the previously mentioned categories and were observed among married couples. These involved severe psychosexual conflicts, often in both partners, and usually centered around the wife's need to punish and humiliate her husband. When the pregnancy was known, this was a test for the husband to be courageous and in his ability to stand by her. The husbands involved were submissive and passive, and looked for guidance from their wives. ${ }^{13}$

His major consensus is that because the sexual relationship is often the closest of human interpersonal relationships, it is axiomatic that any aspect of contraception or its omission that enters into heterosexual intercourse is likely to be interwound with the personalities, fantasy lives, and major conflicts of the sexual partners. He further states that "contraceptives thus may become also a means of control, reward, manipulation, or punishment." 14

Rainwater, in a pioneering study, described a variety of psychosexual conflicts which led to birth control failure. This study was done among married couples in the poor white urban society. His findings were (1) hostility of the wife toward the husband interested only in his own sexual gratification; (2) women distrusting the male to take the responsibility for contraception, and their own distaste of using the diaphram; and (3) the difficulty of the group interviewed in relating known methods of birth control to their own personal lives. 15

$$
\begin{aligned}
& 13 \text { Ibid., pp. 178-179. } \\
& { }^{14} \text { Ibid., p. 171。 } \\
& { }^{15}{ }_{\text {Ibid., p. } 171 .}
\end{aligned}
$$


Dr. Warren Miller states that Dr. Wolf's findings run strikingly parallel to his unpublished findings. The three categories Dr. Miller describes are: (1) method failure, which occurred in one-third of his patients; (2) not having access to contraception, which effected only three percent of women; and (3) where the psychological and behavioral antecedents to conception play a role in the occurrence of an unwanted pregnancy, and are "complex and by no means primarily a matter of a conscious or unconscious wish to get pregriant."16 He saw the three most common factors involved in the third area as: (1) use by the respondent of the mechanism of denial; (2) use of the mechanism of rationalization; and (3) fear of the side effects of certain contraceptives. 17

In another study titled "Repeat Abortions in New York City: 19701972", it was found that the number of women seeking repeat abortions and the proportion of repeats to total abortions are sma11, but both have increased with time. Of the 114,702 abortions performed on New York City residents over the two-year period, 6,936 (two percent) were repeat abortions. Their study showed that teenagers 17 or younger exhibit the smallest proportion of repeats, followed by women 35 and older. They felt that the differences by age may be explained by differences in fecundity and intercourse frequency. Eighty-six percent of the respondents had told a counselor following their repeat abortion that they wanted to begin a contraceptive regimen before being discharged from the hospital. Fifty-nine percent, however, left the hospital after their repeat abortion without being started on the method

${ }^{16}$ Medical Aspects of Human Sexuality, p. 186 。

17 Ibid., p. 189. 
which they requested. Nearly half (46 percent) of those who requested contraception were given no method at 211 , and an additional 40 (13 percent) were given a different method--generally a less effective one-than they had requested. Following completion of this study in 1972, several municipal hospitals modified their policies to increase contraceptive initiation before discharge. ${ }^{18}$

In summary, the literature as it relates to our study indicates that psychological factors and not lack of adequate information are the causes of abortions and repeat abortions. In the case of the study specifically on repeaters, there may have been medical negligence on the. part of the medical staff who did not follow through on the requested birth control method, but the women did not take the initiative to demand a contraceptive and went without. This, then, may also be a psychological factor, whether it be a form of denial or rationalization. The literature review showed that even when birth control information was readily available, women still have unwanted pregnancies. However, research was limited on the factors behind repeat abortions and on the factors leading to repeat abortion in the Northwest, specifically the Portland area. On this basis, the researchers chose to study factors leading to repeat abortions in the Portland area.

One thing which became clear after doing the literature review is that more studies need to be done in depth into the psychological behavior of both men and women regarding use and misuse of contraception. These are important so that we may become more adept at develop-

18" Repeat Abortion in New York City: 1970-1972," Family Planning Perspectives, Vo1. 5, No. 2, p. 93. 
ing predictive indices that will enable practicioners to identify their problem patient groups prospectively rather than after the occurrence of an unwanted pregnancy. 


\section{CHAPTER III}

\section{METHODOLOGY}

This chapter will describe the methodology used in this study. Initially, the research design will be described. In addition, this chapter defines assumption categories and describes the development of the questionnaires. It will also include a description of the sample, method for collecting data, and the kind of data analysis to be used.

\section{Research Design}

To measure causes behind women having more than one abortion, a questionnaire was developed and administered to actual clients. To achieve this purpose, a questionnaire will be designed which will include the major factors behind women having unwanted pregnancies.

The purpose of the design is accomplished by giving the questionnaire to female clients who have had more than one abortion. The rationale for giving the questionnaire only to repeaters is to identify the causes of repeating, thus helping to identify the common failures. The first site was the University of Oregon Medical School Outpatient Clinic and Multnomah Hospital. The second site was Lovejoy Specialty Hospital.

Development of the Questionnaire

To collect data on the trends suggested by the hypotheses, a questionnaire was developed for clients. The first five questions covered demographic information. The next four questions asked for 
information about birth control and past abortions. Question ten on the questionnaire, which comprised the data for identifying the causes behind repeat abortions, was based on the two areas of investigation previously defined.

A maximum of nine statements, which described reasons for repeated pregnancies, were listed in this section. A previous list of reasons was narrowed by the researchers to these nine statements. Specific assumptions, such as, "I could not afford to see a doctor," and "My doctor took me off birth control," were made into one statement: "Birth control was not used at all." Our purpose for this was to keep the questionnaire short and concise, to ensure the highest rate of returns.

Questionnaire Format

The format of the questionnaire is divided into four sections: the introductory letter, instructions, demographic information, and the body of the questionnaire (see Appendix for a copy of the Questionnaire).

The introductory letter explains who the researchers are, the purpose of the questionnaire, gives directions as to where to return the questionnaire upon completion, and assures the client of confidentiality。

Instructions explain what the information will be used for and again assures confidentiality。

The primary purpose of the first nine questions was to describe the respondents as to age, education, marital status, number of previous live births, number of abortions, prior birth control information, and questions regarding prior abortions. 
Pre-Test ,

The questionnaire was evaluated by three of the Social Service Staff at the University of Oregon Medical School. Feedback on specific statements was helpful in assuring that the intended meaning of the statements was understood and was useful in clarifying ambiguous questions. Irrelevant data was also acknowledged and eliminated, which shortened the questionnaire.

It was then revised and given a two-week trial, period at the Medical School. After the two weeks, the returned questionnaires showed that (1) most clients understood the questionnaire and could fill it out easily, and (2) women were not, on the whole, reluctant to fill out the questionnaire.

Site

The Agency. In seeking an agency that would allow access to actual clients to whom the questionnaire would be given, it was decided to use two of the agencies in town that were serving voluntary female abortion clients. Lovejoy Specialty Hospital and the University of Oregon Medicar School Outpatient Clinic and Multnomah Hospital met this criteria.

Lovejoy Specialty Hospital is a medical facility which is licensed exclusively by the Board of Health for termination of pregnancy. It is set up as an out-patient facility, and therapeutic abortions are performed at the Hospital on a one-day basis. Lovejoy Specialty Hospital is located at 933 N.W.25th. Therapeutic abortions are performed between the 8th and 12th weeks of pregnancy, and patients are referred to other physicians to handle the procedure when the patient is past the 
12th week of pregnancy。 Counseling for the patient is an integral part of the care, plus birth control information, and a two-week check-up. Payment for their services must be made in full and in advance. Because of the system of payment, only those women who can afford $\$ 152.00$ or are on welfare can partake of their services.

The therapeutic abortion service at the University of Oregon Medical School Outpatient Clinic and Multnomah Hospital has been in existence since January 1971. Since its inception in 1971 to 1973, they have performed approximately 1,060 abortions by the suction dilation curettage method. At present, they serve seven abortion patients a week. Six patients are treated with the D\&C method. One patient, who is between 16-20 weeks along in her pregnancy, is being treated by the sal ine method.

\section{The Population}

A11 clients who were seeking their first abortion were not considered for this study. This process resulted in a sample that was more time consuming and was difficult to obtain, yet met the requirements of our study.

In addition, the questionnaire was passed out in two different agencies. This was achieved by creating the same questionnaire and administering it at Lovejoy Specialty Hospital and the University of Oregon Medical School. (Procedure of the administration of the questionnaire is explained in the data collection section following.) 
Data Collection

To collect this data at the University- of Oregon Medical School, the counselors in the abortion clinic gave a questionnaire to every woman who said she had had a previous abortion during her initial interview. The client then returned the completed questionnaire to the secretary at the Social Service Office.

At the Lovejoy Specialty Hospital, the researchers themselves approached women who were (1) waiting for their two week check-up or (2) were waiting for an appointment with a doctor or counselor. This method led to some uncomfortable feelings on the part of the researchers; since the researchers were total strangers to the clients, and did not have privacy in which to answer any questions the client sometimes had. Because of the Administration's policy, this was the only procedure avajlable to the researchers.

The researchers identified the clients who were having a repeat abortion by handing each woman a questionnaire that had a cover letter attached giving directions to only fill out the questionnaire if they had had more than one abortion. Those women who were not repeat abortion clients handed back the questionnaire. Those who chose to fill out the questionnaire were told where to place it when they were through.

The questionnaire was administered over a nine-month period of time, which was from June 15, 1976, through December 31, 1976. 
Totals of Data Collected

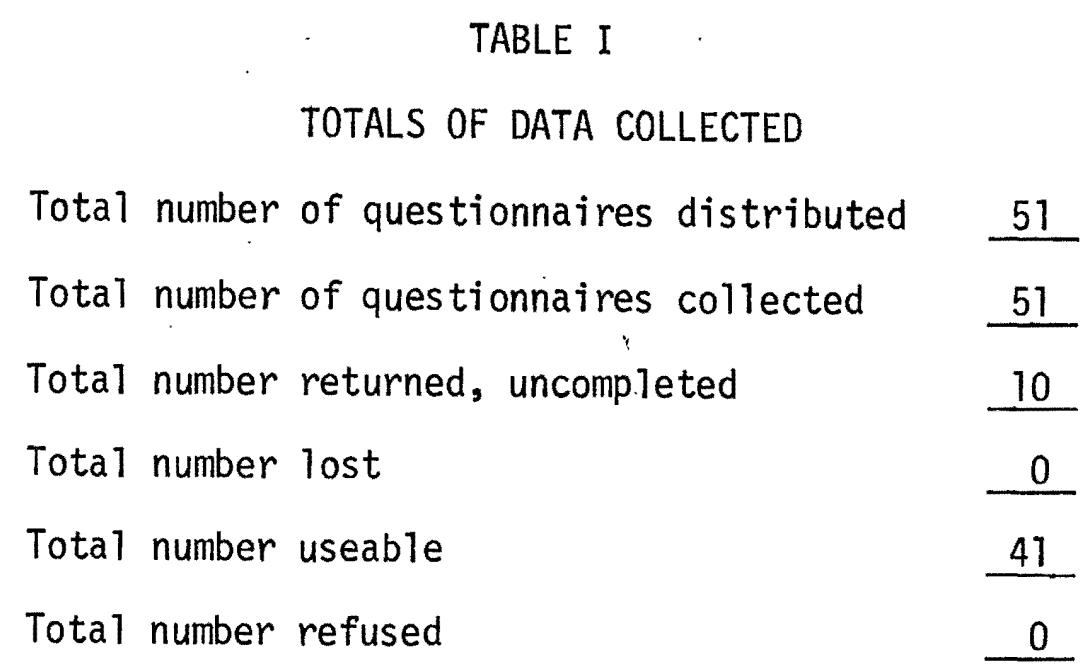




\section{CHAPTER IV}

\section{RESULTS OF DATA}

This chapter will describe the sample based on demographic information obtained from the questionnaire. It will also include the results compiled from each question.

This section includes tables on demographic variables and narrative comments.

TABLE II

AGES OF INTERVIEWEES

\begin{tabular}{|ccc|}
\multicolumn{1}{c}{$f$} & $\%$ \\
\hline $16-18$ & 6 & 15 \\
\hline $19-21$ & 14 & 34 \\
\hline $22-24$ & 8 & 20 \\
\hline $25-27$ & 9 & 22 \\
\hline $28-32$ & 4 & 10 \\
\hline Total & 41 & $100 \%$ \\
\hline
\end{tabular}

The range of ages for persons responding to the questionnaire was 22 years. Most people fell into the category of 19-21 years (34\%). The lowest number of persons falling into one age category was 10 people, falling into the $28-32$ years $(10 \%)$. 
TABLE III

HIGHEST LEVEL OF EDUCATION COMPLETED

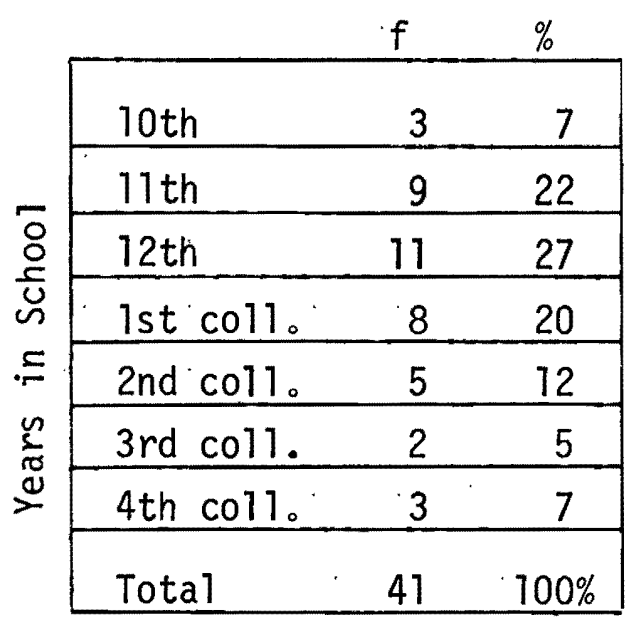

The range of education completed was 10th grade through graduation from college. The average year completed was 12th grade. Most persons fell into the category of having completed the 12th grade $(27 \%)$ 。 The smallest frequency of persons falling into a category was $3 r d$ year of college $(5 \%)$ 。

TABLE IV

LIVING STATUS

\begin{tabular}{|c|c|c|c|}
\hline & & $f$ & $\%$ \\
\hline \multirow{3}{*}{ 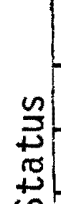 } & Single & 19 & 46 \\
\hline & Màrried & 8 & 20 \\
\hline & Divorced & 4 & 10 \\
\hline & Separated & 3 & 7 \\
\hline$\frac{m}{s}$ & Living With & 4 & 10 \\
\hline 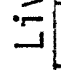 & Other & 3 & 7 \\
\hline & Total & 41 & $100 \%$ \\
\hline
\end{tabular}

The largest percent of interviewees were single. The lowest amount of responses fell into two categories: separated $(7 \%)$ and other 
responses $(7 \%)$.

TABLE V

FREQUENCY OF LIVE BIRTHS

PRIOR TO THIS ABORTION

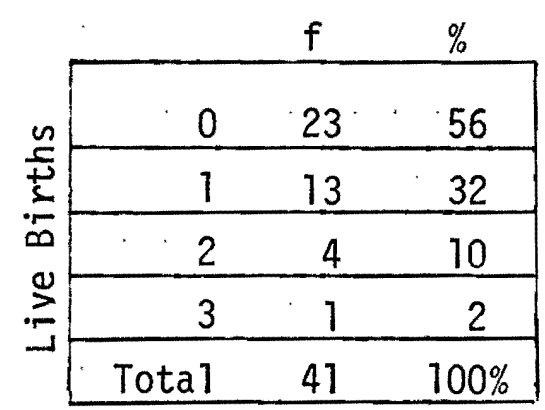

Most of the interviewees had no live births prior to this abortion (56\%). Thirty-two percent of the women had one live birth prior to the abortion. Ten percent of the women had two live births, and $2 \%$ of the women had three live births prior to the abortion.

\section{TABLE VI}

TOTAL NUMBER OF ABORTIONS

INCLUDING LAST ABORTION

\begin{tabular}{|rrr|}
\hline & $f$ & $\%$ \\
\hline 2 & 33 & 81 \\
\hline 3 & 5 & 12 \\
\hline 4 & 3 & 7 \\
\hline Total & 41 & $100 \%$ \\
\hline
\end{tabular}

The lowest number of abortions were two. The highest number of abortions received by an interviewee were four. Most persons fel1 into the category of two abortions. 
TABLE VII

FREQUENCY OF RESPONDENTS HAVING RECEIVED

BIRTH CONTROL INFORMATION

\begin{tabular}{|c|c|c|}
\hline & f & $\%$ \\
\hline Yes & 41 & 100 \\
\hline No & $\therefore$ & - \\
\hline Tota 1 & 41 & $100 \%$ \\
\hline
\end{tabular}

A11 respondents received $100 \%$ of the birth control information.

TABLE VIII

BIRTH CONTROL INFORMATION RECEIVED BY RESPONDENTS

\begin{tabular}{|c|c|c|c|c|c|}
\hline & $\begin{array}{l}\text { Birth } \\
\text { Info. }\end{array}$ & $\begin{array}{l}\text { ontrol } \\
\text { eceived }\end{array}$ & $\begin{array}{r}\text { Bir } \\
\text { Info. }\end{array}$ & $\begin{array}{l}\text { Control } \\
\text { Received }\end{array}$ & Total \\
\hline IUD & $\begin{array}{l}f \\
33 \\
\end{array}$ & $\begin{array}{r}\% \\
80 \\
\end{array}$ & $\begin{array}{r}f \\
8 \\
\end{array}$ & $\begin{array}{l}\% \\
20 \\
\end{array}$ & $\begin{array}{l}\% \\
100\end{array}$ \\
\hline Pills & 39 & 96 & 2 & 4 & 100 \\
\hline Diaphram & 28 & 68 & 13 & 32 & 100 \\
\hline Foam & 21 & 57 & 20 & 49 & 100 \\
\hline Rhythm & 21 & 51 & 20 & 49 & 100 \\
\hline Douch & 21 & 51 & 20 & 49 & 100 \\
\hline Condom & 26 & 63 & 15 & 37 & 100 \\
\hline Withdrawal & 17 & 41 & 24 & 59 & 100 \\
\hline Other & 1 & 2 & 40 & 98 & 100 \\
\hline
\end{tabular}


TABLE IX

LOCATIONS OF PREVIOUS ABORTIONS

\begin{tabular}{|c|c|c|c|}
\hline & & $f$ & $\%$ \\
\hline \multirow[b]{2}{*}{2} & Lovejoy & 17 & 41 \\
\hline & Univ. of Cal: & 4 & 10 \\
\hline 한. & Med.School & 3 & 8 \\
\hline ర్ & Other & 17 & 41 \\
\hline & Total & $47^{\circ}$ & $100 \%$ \\
\hline
\end{tabular}

The largest percentage of places listed were at Lovejoy Specialty Hospital and other outside facilities. Other places listed were outof-state clinics such as New York, Denver, City of Roses.

TABLE $X$

LENGTH OF TIME LAST REPEAT ABORTIONS OCCURRED

\begin{tabular}{|lcc|}
\multicolumn{1}{c}{$f$} & $\%$ \\
\hline Less than 6 mos. & 30 & 73 \\
\hline 6 mos. -1 yr. & 1 & 2 \\
\hline 1 yr. -2 yr. & 6 & 17 \\
\hline 2 yr. -4 yr. & 2 & 4 \\
\hline 4 yro -8 yr. & 2 & 4 \\
\hline 8 yr. or more & 0 & - \\
\hline Total & 41 & $100 \%$ \\
\hline
\end{tabular}

It is interesting to note most persons having repeat abortions occurred mostiy less than six months ago. Two percent of the repetition of abortions occurred six months to one year ago. 
TABLE XI

CAUSES GIVEN FOR PREGNANCY

\begin{tabular}{|lcc|}
\multicolumn{1}{l}{} & $f$ & $\%$ \\
\hline Birth control method not used regularly & 15 & 36 \\
\hline Birth control method failed & 8 & 19 \\
\hline Birth control method not used at all & 8 & 19 \\
\hline Forced intercourse & 0 & - \\
\hline Nervous about exam & 0 & - \\
\hline No birth control information & 0 & - \\
\hline Didn't like birth control method & 6 & 15 \\
\hline Thought "I" was sterile & 3 & 9 \\
\hline Other & 1 & 2 \\
\hline Total & 41 & $100 \%$ \\
\hline
\end{tabular}

Thirty-six percent of the interviewees did not use birth control devices regularly. Nineteen percent of the women did not use birth control at all or the birth control method failed. Fifteen percent of the respondents did not like the birth control method. Nine percent of the respondents thought they or their partners were sterile. Two percent had other reasons. 
CHAPTER $V$

CONCLUSIONS AND IMPLICATIONS

This final chapter will describe conclusions regarding the hypotheses, limitations of the study and implications for social work.

\section{CONCLUSIONS REGARDING THE HYPOTHESES}

This section will explore the original hypothes is in relation to the results of the questionnaire, to determine if the results support the hypothesis. It will also offer possible reasons why clients responded as they did to specific questions.

It was hypothesized in our study that repetition of abortions may be affected by factors such as (1) inadequate birth control counseling and (2) lack of adequate birth control methods. This implies that there are inadequate resources within health institutions which are unavailable to meet the needs of women. From the study the researchers found the following information.

A11 the interviewees had received some birth control information. One-hundred percent of the respondents reported that at one time they had received birth control information. The question did not ask how specific or thorough the information was or how much of the information the women retained. For example, even though a woman stated she had received information about every method, we do not know if this information was given during an hour discussion or a five minute discussion. 
The researcher's first hypothesis was not supported by the results of the data. The results showed that $100 \%$ of the women did receive birth control information; so lack of birth control information as measured did not contribute to repetitive abortions." This is consistent with findings reported by Sanford R. Wolf, M. D. and cited in the literature review of this study.

The second hypothesis suggested that repetition of abortions was caused by inadequate birth control methods. It was found by the researchers that only 19\% of the respondents reported that a birth control method failed. Thirty-six percent of the birth control methods were not used regularly and $19 \%$ of the respondents indicated that a birth control method was not used at a11. Fifteen percent of the respondents did not like any birth control method. "These results suggest that the repetition of abortions were not caused by inadequate birth control methods.

It is interesting to note that the attitudes of the respondents varied. Thirty-six percent of the birth control methods were not used regulariy and 19\% of the birth control methods were not used at a11. It is the opinion of the researchers that the respondents who fell into these two categories may not have been satisfied with the birth control methods available or did not see an importance in using them on a regular basis. The data did show that $15 \%$ of the women were dissatisfied with the available birth control methods. The researchers concluded, from the above data that there are varied attitudes toward available birth control methods and these attitudes could have an effect on repetitive abortions. 
Other conclusions can be made regarding the data collected by the researchers. Below is a general summary of the important points to be considered.

The youngest persons who took the survey were 16 years of age. The 01 dest was 32 years of age. The average age was 22 years。

The average year completed in school was 12th grade. The lowest grade of education received was 10 th grade, and the highest grade completed was college graduation.

The largest group of participants were single women. The highest incident of live births prior to the abortions were three. Most had no prior live births.

The lowest number of repetitive abortions were two. The highest number was four. The average number of repetitive abortions was 2.07. One-hundred percent of the women received some type of birth control information. Ninety-six percent of the women received information about birth control pills, that being the largest percentage of information received.

Most previous abortions were performed at Lovejoy Medical Hospital or various clinics throughout the United States.

of the $73 \%$ of the persons having repetitive abortions, these abortions occurred less than six months ago.

Thirty-six percent of the women did not use birth control regular1y. Nine percent did not use any birth control method at all or the method failed.

This suggests that the respondents were mostly single women about the age of 22 who had completed high school. It is possible that these findings will be important for further research on repetitive abortions. 


\section{LIMITATIONS OF THE STUDY}

One of the main purposes of this study was to determine the motivational factors behind repeat abortions. This section will examine possible factors that were revealed by the data from our study and retrace the limitations of this study.

The original purpose of this study was exploratory in nature. The researchers attempted to establish whether there are any significant factors in the causation of repeat abortions. To accomplish this purpose an instrument was developed and administered to women who had had repetition of abortions.

In retrospect, it has become apparent that the researchers used three steps in the process of the development of the study。

The first was to create two underiying assumptions: (1) women. have abortions; (2) women have repeat abortions. The second step of the process was to develop two research questions based on the above assumptions: (1) are there significant factors in the causation of repeat abortions; and (2) what are the implications regarding the lack of information and service to women which have a direct relationship to repeat abortions. The third step was to develop two hypotheses: repetition of abortions is caused by inadequate counseling; and (2) repetition of abortions is caused by lack of adequate birth control methods.

Because each of these steps could have been a study in and of itself, and because these researchers attempted to do all three, the purpose of this study was not fully accomplished。

There are several reasons why the instrument developed for this 
study was not as useful as expected. The questionnaire format was too general and did not gather specific responses. Instead, it assumed that specifics could be inferred by the researchers from these general questions. Perhaps a second questionnaire focusing more on specific areas should have followed the initial general questionnaire, therefore offering the researchers more specific data. It was impossible to conclude from the way in which the questions were stated, or the way in which the directions were read, whether this elicited more general responses rather than specific data. An example of this are the responses to question Number 7, which measured which birth control methods respondents had information about, but did not measure how much of the information they retained was reliable and factual. A more extensive pre-test would have helped to validate the instrument. Finally, there was no effort to compare this instrument with any other validated instruments.

After obtaining the data, it became apparent that there was one factor related to the sample that may have influenced the results of this study. The questionnaire was administered to only those women who were repeating an abortion. It is in the opinion of the researchers that the women answering these questions were under some degree of stress and discomfort. Because the questionnaire was administered at the hospital preceding a medical examination after the previous abortion, some of the women seemed somewhat uncomfortable and nervous; therefore, this may have been a factor influencing their responses (i.e., hurrying through the questionnaire, not following directions, etc.).

Another factor related to the sample that may have influenced the results of this study was not having specifically asked what birth con- 
trol methods a woman used previous to each abortion." Therefore, the information received was not thorough.

\section{IMPLICATIONS FOR SOCIAL WORK}

This section will discuss what implications this study has for women in our society and practicing abortion counselors.

From our study it is: important to note that some women do experience more than one abortion. Repeat abortions do occur among women. The following factors may have an influence on further study about repetitive abortions.

(1) Since abortions became legal in 1970 , women now have another recourse besides having unwanted children. An abortion is no longer difficult to obtain.

(2) There are women who have repeat abortions; therefore, it may be important to consider with further research the importance of more support from women's health institutions and literature concerning repetitive abortions.

(3) From the literature review the researchers learned that there are psychological factors that are related to abortions. Some of the noted psychological factors were: feelings of inefficacy, impulsive in decision-making, self-punishing, psychosexual conflicts, etc。

The researchers believe that there are a combination of reasons that cause women to experience repeat abortions. For future study and better service delivery, it might be important to consider the follow ing: 
(1) That $100 \%$ of the women in this study did receive birth control information and because of varied attitudes or the way in which the information was delivered, the respondents did not use the methods consistently. It is the opinion of the researchers that further study is needed in the area of women's attitudes toward birth control methods.

(2) Seventy-three percent of the repeat abortions occurred less than six months ago. Women are continuing to have repeat abortions in the present. In a study performed in New York City, within the first time period of six months there was a total of 2.27 repeat abortions; and in the second time period, also six months, a total of 6.02 repeat abortions were performed. "The number of women seeking repeat abortions in proportion to first time abortions is sma11, but increased in time.

(3) Most respondents who have repeat abortions are 22 years of age and have completed high school. This is important considering that a common myth among professionals is that repetitive abortions occurs mostly among young teenage girls.

The above points may contribute to further study concerning the problem of repetitive abortions. This study establishes no conclusive evidence as to why repetitive abortions occur among women; however, it is hopeful that the issue of repetitive abortions will become a concern to society as a whole. 


\section{BIBLIOGRAPHY}

Abernethy, V., J. Grunebaum, B. Groover, and L. Clough, "Contraceptive Continuation of Hospitalized Psychiatric Patients," Family" Planning Perspectives, 7 (5), Sept。-0ct. 1975, Federation of America, Inc。, New York, 1969, pp. 231-234。

Aldous, Joan and Nancy Dahl, International Bibliography of Research In Marriage and the Family, Vol. II, University of Minnesota Press, Michigan, 1965-1972。

Angrist, S. S., "Communication About Birth Control: An Exploratory Study of Freshman Girls 'Information and Attitudes," Journal of Marriage and the Family, Vol. 28, The National Council on FamiTy Relations, Wisconsin, T966, pp. 284-286.

Badauhorst, L. To, "Family Limitation and Methods of Contraception in an Urban Population," Population Studies, Vo7 . 16, Population Investigation Committee, London, 1963, pp. 286-301.

Beck, M. B., "Abortion, A National Public and Mental Health Problem Past, Present and Proposed Research," American Journal of Public Health, Vol。59, American Public Health Association, New York, 1969, pp。2131-2143。

Burche11, R。Clay, "Professional Perspectives on Abortion," Journal of Obstetrics, Gynecology and Neonatal Nursing, Harper and Row, Hagers town, Maryland, 1974.

Bureau of Community Health Services, Health Services Administration, Department of Health, Education and Welfare, "Health, Social Impact of Legalized Abortion," Family Plarining Digest, Vol。I, No. 4, Center for Family Planning Program Development, New York, 1972, pp. 13-15.

Crowley, R。M。 and R。W. Laidlaw, "Psychiatric Opinion Regarding Abortion," American Journal of Psychiatry, Vo1. 124, American Psychiatric Association, Washington D。C., Oct。1967, pp。559-562。

Daily, Edwin Fo, M. D., Nick Nicholas, Frieda Nelson and Jean Parker, M。D., Family Planning Perspectives, Vo1。5, No。2, Sp。 1973.

Fork, Ko, "Abortion and Family-Binding Models: Fertility Limitation in Hungary," Demography, Vol. 13 (4), Nov. 1976, Population Association of America, Washington, D. C., 1964, pp。495-505. 
Kanitkar, S. D。 and V. Walvekar, "Clinical Experience with Menstrual Regulation," Journal of Obstetrics and Gynaecology in India, 25 (6), Dec. 1975, Federation of Obstetrics and Gynaecological Societies of India, Bombay, 1950, pp.783-786.

Keith, L., D. Keith, R。 Busse11, J. Wells, "Attitudes of Men Toward Contraception," Arch Gynaekó1, 220 (2), Dec. 1975, SpringerVerlag, West Germany, 1870, pp。89-97.

Keller, A. B., J.H. Sims, W. E. Henry, T. J. Crawford, "Psychological Sources of Resistance to Family Planning," Merrill-Palmer Quarterly, Vol. 16, Merril1-Palmer Institute, Michigan, 1970, pp. 286-302.

Lauersen, H. H., K. H. WiTson, I. A. Zervoudakis, Z. Saary, "Manágement of Failed Prostaglandin Abortions," Obstetrics and Gynaecology, 47 (4), Apr. 1976, Harper and Row, Hagerstown, Maryland, 1952, pp。473-478。

Liu, P. T. and L. P. Chow, "The Efficiency of the Multiple Trial Randomized Response Technique," Biometrics, 32 (3), Sept. 1976, Biometric Society, Raleigh, North Carolina, 1945, pp. 607-618.

Luker, Kristin, Taking Chances: Abortion and the Decision Not to Contracept, University of California Press, Berkeley, 1975.

Newman, S. H. and M. B. Beck, "Abortion, Obtained and Denied: Research Approaches, "Studies in Family Planning, (5), May 1970, Population Council, New York, 1963, pp. T-8.

Palomaki, Jacob F。, M. Do, "Abortion Techniques: What are their Risks and Complications," Contemporary Obstetrics and Gynecology, Vol. 9, McGraw-Hi11, Inc., New York, January 1977.

Presley, Roberta, Report on Recidivism, Cleveland Center for Reproductive Health, Cleveland, 1976.

Robins, J., "Failures of Contraceptive Practice," New York State Journal of Medicine, 76 (3), Mar。 1976, Medical Society of the State of New York, Lake Success, New York, 1901, pp。361-365.

Rosenthal, M。 B. and E. Rothchild, "Some Psychological Considerations in Adolescent Pregnancy and Abortion," Adv. Planning Parent, 9 (3-4), Elsevier, New York, 1975, pp. 38-44。

Su, I. H. and L. P. Chow, "Induced Abortion and Contraceptive Practice: An Experience in Taiwan," Studies in Family Planning, 7 (8), Aug. 1976, Population CounciT, New York, 1963, pp. 224-230。

Wolf, Sanford R., M。 D., "Psychosexual Problems Associated with the Contraceptive Practices of Abortion-Seeking Patients," Medical Aspects of Human Sexuality, Vol。VII, No。9, Clinical Communication, Inc., New York, September 1973. 


\section{APPENDIX}

\section{QUESTIONNAIRE}

This questionnaire is designed to help us determine why repeat abortions occur. It is hoped that with this knowledge we can better serve you and also pinpoint where further work and research needs to be done. Do not put your name on this questionnaire. All information will remain confidential.

1. Age:

2. Education: (highest grade completed)

3. Status:

Married

Single

Divorced

Separated

Widowed

Living with significant other

4. Number of previous live births:

5. Including this abortion, how many abortions (legal or illega1) have you had? 
6. Have you ever received birth control information by a trained professional, i.e., women's health center, nurse, teacher, doctor, etc。?

yes no

7. If you answered yes to the above question, check which ones you have received information about:
A。 IUD
B. Birth control pills
C. Diaphram \& Jelly
D. Foam, cream
E. Rhythm method
F。 Douching
G. Condom
H. Withdrawal
I. Other:

8. Where were your past abortion(s) performed?
A.
B。
C。
D。 
9. PAST ABORTIONS (how long ago)

Please fill in the blank spaces below with a number response from the right hand column。

(example: 1st abortion 3 )

A. 1st abortion

B. 2nd " - $\begin{aligned} & \text { 1. Less than } 6 \text { months ago。 } \\ & \text { 2. } 6 \text { months to } 1 \text { year ago. }\end{aligned}$

C. 3rd "

3. 1 year to 2 years ago.

D。 4 th

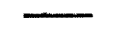

4. 2 years to 4 years ago。

E. 5th

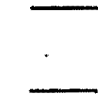

5. 4 years to 8 years ago.

F。 6th "

6. 8 years or more.

G. Last "

10. REASON FOR PREGNANCY

Please select appropriate answer from the right hand column and fill in the blanks below with a number.
A. 1st abortion
B. 2nd

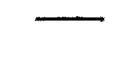
C. 3rd "
D. 4th "
E. 5th "
F. 6th "
G. Last "
H. Present "

1. Birth control not used regularly.

2. Birth control method failed.

3. Birth control was not used at al1.

4. Forced intercourse; no chance to use birth control method.

5. I was nervous about seeing a doctor for a pelvic and birth control.

6. I had no birth control information.

7. I stopped usirig any birth control because I didn't like what I had. I waited for something better.

8. I thought I was sterile; I thought my sexual partner was sterile.

9. 0ther: (don't remember, don't know why, etc.). 